\title{
Strategies to Boost the Uptake of Voluntary Counselling and Testing (VCT) by University Students
}

\author{
Mbengo $F$ \\ Department of Child Welfare South Africa, QwaQwa, \\ P. O Box 6031, Phuthaditihaba, 9866. South Africa \\ Email: fmbe2002@yahoo.com
}

Ngirande $\mathrm{H}$

Department of Business Management, University of Limpopo (Turfloop Campus) Email: hlanganipai@gmail.com

Ndou ND

Advanced Nursing Science Department, University of Venda, South Africa

Mavundla TR

Department of Health Studies, University of South Africa, P O Box 392, Unisa. South Africa, 0003

Doi:10.5901/mjss.2014.v5n15p458

\begin{abstract}
Voluntary counselling and testing (VCT) is internationally recognised as a gateway to HIV prevention, care and treatment. However, VCT uptake among university students is still low. As there is presently no cure for HIV/AIDS, strategies to boost VCT uptake among university students are critically important. This study explored the strategies to improve the uptake of VCT by university students. The study employed an exploratory and descriptive qualitative study. Focus group discussions (FGD) and field notes were used to collect data. Analysis was done using thematic analysis. The study revealed that VCT services uptake for university students could be improved by increased resource allocation (incentives, human and infrastructural resources), increased awareness campaigns, and improved counselling and making VCT services more accessible.
\end{abstract}

Keywords: HIV, AIDS/HIV-antibody testing, voluntary, counselling.

\section{Introduction, Background of the Study and Problem Statement}

Globally, Human Immunodeficiency Virus infection/Acquired Immunodeficiency Syndrome (HIVIAIDS) epidemic continues to be the leading cause of morbidity and mortality (UNAIDS, 2011). Sub-Saharan Africa remains the most affected region in the world with an estimated 22.5 million people living with HIV (Charles, Kweka, Mahande, Barongo, Shekalaghe, Nkya, Lowassa, \& Mahande, 2009.) South Africa with an estimated 5.6 million people living with HIVIAIDS bears the highest HIVIAIDS burden than any other country in the world (UNAIDS, 2011). The South African higher education sector is no exception and is being affected fundamentally by the epidemic (HEAIDS, 2010). University students fall within the sexually active segment of the population, hence are at risk of contracting HIV.

Various preventive strategies such as abstinence, avoidance of multiple sexual partners, condom use, Voluntary Counselling Testing (VCT), male circumcision and treatment of HIV-infected individuals have been employed to curb the spread of infection as there is presently no cure (Daniyam, Agaba, \& Agaba, 2010). VCT is a process in which an individual undergoes counselling, enabling him or her to make an informed choice about being tested for HIV (Izugbara, Undie, Mudege \& Ezeh, 2009). According to Granich, Gilks, Dye, De Cock and Williams (2009), the benefits of knowledge of HIV status can be seen at the individual, community and population levels. These include: For the individual - enhanced ability to reduce the risk of acquiring or transmitting HIV; access to HIV care, treatment and support; and protection of unborn infants. For the community - a wider knowledge of HIV status and its links to interventions can lead 
to a reduction in denial, stigma and discrimination and to collective responsibility and action. At the population level knowledge of HIV epidemiological trends can influence the policy environment, normalize HIVIAIDS and reduce stigma and discrimination.

Despite the usefulness of VCT as an entry point to prevention for the HIV-uninfected people and care, treatment and support for those who test HIV positive, VCT uptake among various student populations is still low. In Zimbabwe, for example over $90 \%$ of students had heard about VCT, but just a quarter of the students had undergone VCT (Madehwe, Pazvakavambwa \& Muringanidza, 2012). In Ghana, only $45.4 \%$ of the students had tested for HIV despite over $95 \%$ of the students being knowledgeable about where to get an HIV test (Oppong Asante, 2013).

According to HEAIDS (2010), by the year 2005, 74\% of the higher education institutions in South Africa had established VCT services, with $69 \%$ of these providing VCT for free. Although several South African higher education institutions had set up VCT services, VCT utilisation among university students remains lower than projected, for example, never testing was highest among South African university students at 54\% (HEAIDS, 2010). The documented reasons for low VCT utilisation among university students include; HIVIAIDS related stigma and discrimination, fear of a positive result, concerns about confidentiality, having a false sense of security, costs of HIV testing and inaccessible VCT sites, long distance of travel to the nearest VCT site, inadequate VCT staff and counselling rooms and lack of awareness, knowledge and benefit of VCT (Meiberg, Bos, Onya \& Schaamal, 2008; Vajpayee, Mojumdar, Raina, Mishra \& Sreeinvas, 2009; Ireri, Tumuti, Mathuvi, Njagi, Piero, Gatumu, Njagi, \& Karugu, 2012).

As there is presently no cure for HIVIAIDS, strategies to improve VCT utilisation among university students are critically important. Other studies have focused on strategies to improve VCT uptake among the general population and other population groups such as fishing communities (Matovu \& Makumbi, 2007; Mugisha, van Rensburg \& Potgieter, 2011). Currently, very little information is known regarding studies documenting strategies to improve VCT uptake among university students. Therefore it is necessary to explore the strategies to improve the uptake of voluntary counselling and testing (VCT) by university students.

\section{Objectives of the Study}

i. To explore the nature of strategies of improving the uptake of voluntary counselling testing among university students.

ii. To give recommendations to administrators, policy makers, health care workers and students in higher education institutions on strategies of increasing the uptake of VCT by university students based on research findings.

\section{Research Questions}

1. Does increased resources allocation improves VCT among university students?

2. Do increased awareness campaigns improve VCT among university students?

3. Does improved counselling a better strategy to improve VCT among university students?

4. Does making VCT services more accessible improve VCT among university students?

\section{Research Design and Methodology}

This study is explorative and descriptive and uses a qualitative research design to explore the strategies of improving the uptake of voluntary counselling testing among university students.

Participants were students enrolled at the University of Free State, QwaQwa campus for the 2012 academic year, and were purposefully selected based on their knowledge on VCT services. Purposive sampling was used to ensure that appropriate individuals were selected to provide rich study data (Babbie, 2013). The participants were selected with the help of the campus director of residences and the student representative council who acted as gatekeepers to access the university students (Mbengo, 2013). Focus group discussions (FGDs) and field notes were used to collect data. The data collected during the FGDs was supported by field notes, which were used as part of the data analysis.

\section{Trustworthiness of the Study}

The trustworthiness of the study refers to the criteria used to judge the quality of a qualitative study (Johnson \& Christensen, 2008). The data and the relevant supporting documents were evaluated by an external reviewer who 
concurred with researchers' analysis and interpretation. The external reviewer was a student pursuing a doctorate degree and had vast experience in qualitative research. The focus group interviews and field notes data were gathered at the Free State University (QwaQwa Campus) over a period of four weeks in order to enhance the credibility of the study. Focus group interviews were conducted until no new or relevant data emerged. In total, five focus groups were conducted at the end of the study.

\section{Data Analysis}

Thematic analysis was used to analyse the data. The data from the audiotapes were transcribed verbatim and coded into themes, sub themes and patterns. Key issues around the strategies to improve VCT uptake by university students were explored in detail. The research findings were considered in dialogue with literature and current research in order to offer critique, possible applications, and further directions of research and to enhance rigour of the study.

\section{Results}

The purpose of the study was to explore strategies to boost the uptake of VCT services by university students.

\subsection{Strategies to boost the uptake of VCT services by the university students}

This theme describes participants' suggestions to improve the uptake of VCT services. Four main sub-themes were identified within this theme, describing how the uptake of VCT by university students could be improved. The results of the study are summarised in table 1.

Table 1: Summary of the themes and sub-themes

\begin{tabular}{|l|ll|}
\hline \multicolumn{1}{|c|}{ Themes } & \multicolumn{1}{c|}{ Sub-Themes } \\
\hline $\begin{array}{l}\text { Strategies to improve the uptake } \\
\text { of VCT services by the university }\end{array}$ & $\bullet$ & Increased resources allocation namely: human resources, infrastructure and incentives. \\
students & - & Improved counselling. \\
& - & Making VCT services more accessible. \\
\hline
\end{tabular}

\subsection{Increased resources allocation}

The increased resources allocation was a recurring sub-theme that cut across all the FGDs. Within this sub-theme three main sub-themes emerged namely: human resources, infrastructure and incentives. The FGDs revealed that VCT uptake could be improved by increased allocation of human resources. The participants mentioned that the shortage of nurses/counsellors to provide VCT services was a major factor hindering VCT uptake by university students. The FGDs revealed that there was only one nurse/counsellor at the university providing VCT services to students. The participants complained about the non-availability of this one nurse/counsellor 'most of the times'. Hence the participants suggested that VCT uptake by university students could be improved by employing more nurses/counsellors to provide VCT services.

The participants also mentioned that VCT uptake could be improved by recruiting peer educators to provide VCT. The FGDs revealed that university students could feel more comfortable if VCT is provided by their peers as illustrated by an extract of a participant from focus group $D$ :

\section{D6: ' .......How can I talk to old people about.... (Group members laugh)...my status?'}

The participants also stated they could feel encouraged if the university invites 'celebrities' who are living with the virus to come and talk to them about the importance of knowing one's status.

Participating university students suggested that VCT uptake could be improved by increased infrastructure. The participants complained that there was only one VCT room at the university and this hindered them from seeking VCT as they feared to be seen by other students at the VCT room. They suggested that there should be many VCT rooms at the university in order to encourage students to go for VCT. Driving this point home, a participant from focus group D had this to say: 
"D6: "I think also there should be a lot of places where people can go and test...'.

The other suggestion to boost VCT uptake put forward by participants was the giving of incentives (such as free memory sticks, free televisions and free laptops) to university students in order to encourage their attendance for HIV testing. Elaborating this point a participant from focus group A had this to say:

A8: 'I think like that happened last time, come and get tested and get a memory stick, it was the best!.....'

\subsection{Increased awareness campaigns}

The other important sub-theme that was representative of all the FGDs was the use increased awareness campaigns in order to boost VCT uptake. The participants suggested that VCT uptake by university students could be improved by increased awareness campaigns about VCT. The participants stated that the other reason for not seeking VCT was that they were not fully aware of its existence, purpose and use. They mentioned that awareness campaigns would make university students aware of the existence, purpose and use of VCT. Driving this point home, a participant from focus group D had this to say:

D6: 'Firstly right now we haven't been told about it, they have been passive about VCT...... We can't go to them because we don't know it's there.......'

\subsection{Improved counselling}

Going by the information elicited, VCT uptake by university students could be boosted by improved counselling. The participants suggested that counsellors should provide a comfortable environment for testing by 'making jokes and having a television set' in the counselling room. They suggested that these measures would 'enlighten the mood' during VCT. Illustrating this point a participant from focus group A had this to say:

A2: 'Like it should lighten the mood,......like when you are waiting for the results maybe they should have a television set, sharing some jokes and something like that you know, just to enlighten'.

Furthermore, the participants suggested VCT uptake could be boosted by post-test and follow-up counselling after a person has known his or her status as participant from focus group $E$ puts it:

E5: 'Okay before it comes to me I would suggest that there is counselling after you find out your status ... (pause) okay maybe for a week to get into that zone where you are comfortable okay l'm positive then l'll go to my family and explain actually l'm positive, this is what happened'.

\subsection{Making VCT services more accessible}

The other recurring category obtained from the FGDs was making VCT services accessible in order to boost their uptake. The participants complained that the VCT facility at the university was 'too hideous' for the reach of many students. They said that very few students knew that there were VCT services at the university because they were hardly visible. The participants suggested that VCT services uptake could be boosted by making them more accessible to university students as one participant from focus group A puts it:

\section{A3: 'They should put VCT somewhere we all go for instance DH (dining hall)....'}

\section{Discussion}

The study explored the strategies to boost the use of VCT services by university students. The findings of the study are important to increase VCT uptake by university students. Regarding strategies to improve VCT uptake by university students, participants gave their views on how VCT uptake by university students could be improved. Their recommended measures included: increased resources allocation, increased awareness campaigns, improved counselling and making VCT services more accessible.

The findings of this study are congruent with the results obtained from other studies. The participants suggested that VCT uptake by university students could be improved by increased resource allocation, for example by employing 
more nurses/counsellors and peer educators, establishing more VCT rooms and by providing incentives to attract students. Participants in this study cited the shortage of human and infrastructural resources as factor that dissuaded them from undergoing VCT. Similarly, a study in South Africa revealed that inadequate human resources and counselling rooms, insufficient testing facilities, and a lack of educational materials discouraged people from seeking VCT services (Mavhandu-Mudzusi, Netshandama, \& Davhana-Maselesele, 2007). It is further reported that South Africa is experiencing a chronic shortage of key health professional cadres vital to VCT service delivery (Wadee \& Khan, 2007). Research has further revealed that VCT uptake is high in places with well-resourced VCT services than in places with poorly-resourced VCT services (Sambisa, Curtis, \& Mishra, 2010). Therefore, increased allocation of infrastructural and human resources in VCT centres in order to boost VCT uptake becomes paramount.

Evidence from this study revealed that VCT uptake by university students could be boosted by making VCT services accessible. The university students said that they were discouraged from going for VCT because the VCT services were 'too far and too hideous' for access by students. It is therefore important to increase the accessibility of VCT services in order to increase their uptake by university students. Research has shown that accessible VCT services have high number of people seeking them than inaccessible ones (Angotti, Bula, Gaydosh, Kimchi, Thornton, \& Yeatman, 2009). The provision of VCT in locations and in conditions that are convenient to clients such as at workplaces, health facilities, schools, higher education institutions have been shown to increase utilisation (Obermeyer \& Osborn, 2007). Such approaches to increase accessibility of VCT services in order to boost their utilisation by university students will include: the use mobile VCT and provider-initiated VCT (Matovu \& Makumbi, 2007). A study by Baisley, Doyle, Changalucha, Maganja, Watson-Jones, Hayes \& Ross (2012) revealed than provider-initiated VCT was associated with higher VCT uptake among young people when compared to client-initiated VCT.

The VCT services need to be student friendly in order to make them more acceptable to the university students. Participants in this study were discouraged from going for VCT because the VCT counsellors were old. There is need for VCT services to be provided by other students in order to make them more acceptable to the students. The use of peer counsellors to offer VCT services has been shown to improve uptake. Young people are likely to respond to programmes conducted by their peers. For example, a study among university students revealed that respondents had undergone VCT because of the influence of peers (Njagi \& Maharaj, 2006).

VCT uptake by university students could be improved by increased awareness campaigns about VCT. The other reason mentioned by university students for not seeking VCT was that they were not fully aware of its existence, purpose and use. VCT campaigns on campuses about the existence, purpose and use of VCT are critical step in boosting VCT uptake by university students. Higher education institutions should conduct VCT campaigns to educate university students about the benefits of VCT. Increased awareness campaigns about VCT through a wide range of engaging student-led prevention activities including drama groups, residence workshops, media and marketing projects, marches, games, poetry slams and community outreach boosted VCT uptake by university students (HEAIDS, 2010).

Evidence from the current study suggests that VCT uptake by university students could be boosted by improved counselling. The participants suggested that counsellors should provide a comfortable environment in the counselling room so that they will be encouraged to attend VCT. The participating university students mentioned that the counsellors who conducted the VCT were experienced, supportive and understanding and this motivated them to seek VCT. Research has also shown that poor counselling discourages people from seeking VCT (Daftary, Padayatchi \& Padilla, 2007).

The study has certain limitations. A small sample of university students was used for this study, hence the findings of this study cannot be generalised to other settings. Some of the students refused to participate in the study due to lack of knowledge of the VCT services. University students attended classes at the different sessions and this deterred their attendance of the focus group discussions. However theoretical significance of the study, its applicability to public health practice and its influence on future research activities therefore remain unquestionable.

\section{Conclusion}

This study has explored strategies to boost VCT uptake by university students. The study findings are important to administrators, policy makers, health care workers and students in higher education institutions in increasing the uptake of VCT by university students. 


\section{Acknowledgements}

We are indebted to the UNISA Department of Health Higher Degree Ethical Committee and the University of Free State for granting ethical clearance and approval to conduct the study. We would also like to thank the participants for their time and invaluable input to this study. Without their participation, the study would not have been possible.

\section{References}

Angotti, N, Bula, A, Gaydosh, L, Kimchi, E. Z, Thornton, R. L \& Yeatman, S. E. (2009). Increasing the acceptability of HIV counselling and testing with three Cs: convenience, confidentiality and credibility. Soc Sci Med, 68(12):2263-2270.

Babbie, E. R. (2013). The Practice of Social Research, (13th edition). Cengage Learning.

Baisley, K, Doyle, A. M, Changalucha, J, Maganja, K, Watson-Jones, D, Hayes, R \& Ross, D. (2012). Uptake of Voluntary Counselling and Testing among Young People Participating in an HIV Prevention Trial: Comparison of Opt-Out and Opt-In Strategies. PLos ONE, 7(7): 42-108.

Charles, MP, Kweka, EJ, Mahande, AM, Barongo, LR, Shekalaghe, S, Nkya, HM, Lowassa, A \& Mahande, MJ. (2009). Evaluation of uptake and attitude to voluntary counselling and testing among health care professional students in Kilimanjaro region, Tanzania. BCM Public Health, 9:128.

Daftary, A, Padayatchi, N \& Padilla, M. (2007) HIV testing and disclosure: a qualitative analysis of TB patients in South Africa. AIDS Care, 19(4):572-577.

Daniyam, C. A, Agaba, P. A \& Agaba, E. I. (2010). Acceptability of voluntary counselling and testing among medical students in Jos, Nigeria. J Infect Dev Ctries, 4(6):357- 361.

Granich. R. M, Gilks C. F, Dye C, De Cock. K. M, Williams. B. G. (2009). Universal voluntary HIV testing with immediate antiretroviral therapy as a strategy for elimination of HIV transmission: a mathematical model. Lancet, 373:48-57.

HEAIDS. (2010) HIV prevalence and related factors - higher education sector study, South Africa, 2008-2009. Pretoria: Higher Education South Africa.

Ireri, A. M, Tumuti, D. W, Mathuvi, P. N, Njagi, J. M, Piero, N. M, Gatumu, H. N, Njagi, A..N \& Karugu, N.I. (2012). Sources of VCT information and reasons for use or non-use of VCT services by young people in selected rural locations in Kenya. International Journal of Social Science Tomorrow, 1(2):1-8.

Izugbara, C.O, Undie, C, Mudege, N.N \& Ezeh, A.C. (2009). Male youth and voluntary counselling and HIV-testing: the case of Malawi and Uganda. Sex Education, 9(3):243-259.

Johnson, B \& Christensen, L. (2008). Educational research: quantitative, qualitative, and mixed approaches. $3^{\text {rd }}$ edition. Los Angeles, United States of America: Sage.

Madehwe, V, Madehwe, C, Pazvakavambwa, L \& Muringanidza, K. C. R. (2012). Taking the test: voluntary counselling and testing (VCT) among midlands state university students. Educational Research Journal, 2(1):7-13.

Matovu, J. K. B \& Makumbi, F. E. (2007). Expanding access to voluntary HIV counselling and testing in sub-Saharan Africa: alternative approaches for improving uptake, 2001-2007. Tropical Medicine and International Health, 12(11):1315-1322.

Mavhandu-Mudzusi, A. H, Netshandama, V. O \& Davhana-Maselesele, M. (2007). Nurses' experiences of delivering voluntary counselling and testing services for people with HIVIAIDS in the Vhembe District, Limpopo Province, South Africa. Nursing and Health Sciences, 9:254-262.

Mbengo, F. (2013). Factors influencing the use of voluntary counselling and testing by university students. Unpublished master of public health dissertation. University of South Africa.

Meiberg, A. E, Bos, A. E. R, Onya, H. E \& Schaamal, H. P. (2008). Stigmatization as barrier to voluntary HIV counselling and testing. East African Journal of Public Health, 5(2):49-66.

Mugisha, E, van Rensburg, G. H \& Potgieter, E. (2011). Strategic Framework for Increasing Accessibility and Utilization of Voluntary Counseling and Testing Services in Uganda. AIDS Research and Treatment, 1-9.

Njagi, F \& Maharaj, P. (2006). Access to voluntary counselling and testing services: Perspectives of young people. South African Review of Sociology, 37(2):113-127.

Obermeyer, C. M \& Osborn, M. (2007). The utilization of testing and counselling for HIV: a review of the social and behavioural evidence. American Journal of Public Health, 97(10):1762-1774.

Oppong Asante, K. (2013). HIVIAIDS knowledge and uptake of HIV counselling and testing among undergraduate private university students in Accra, Ghana. Reproductive Health, 10:17.

Sambisa, W, Curtis, S \& Mishra, V. (2010). AIDS stigma as an obstacle to uptake of HIV testing: evidence from a Zimbabwean national population-based survey. AIDS Care, 22(2):170-186.

UNAIDS. (2011). UNAIDS world AIDS day report. Geneva: UNAIDS.

Vajpayee, M, Mojumdar, K, Raina, M, Mishra, S \& Sreeinvas, V. (2009). HIV voluntary counselling and testing: an experience from India. AIDS Care, 21(7):826-833.

Wadee, H \& Khan, F. (2007). Human Resources for Health. South African Health Review, 141-149. 